\title{
Measurements of section pump rotor axial position at Udachny mine
}

\author{
Vikulov Mikhail A. \\ Mining Machines Department \\ North-Eastern Federal University n.a. M.K. Ammosov \\ Yakutsk, Russia \\ gormashygu@mail.ru
}

\author{
Ovchinnikov Nikolay P. \\ Mining Machines Department \\ North-Eastern Federal University n.a. M.K. Ammosov \\ Yakutsk, Russia \\ ovchinnlar1986@mail.ru
}

Makhno Dmitriy E.

Mining Machines and Electromechanical Systems Department

Irkutsk National Research Technical University

Irkutsk, Russia

fai@istu.edu

\begin{abstract}
Analysis of the representative statistical data showed that main causes of frequent expensive major repairs of the section pumps in the pump chamber of the main mine drainage system at the Udachny mine are failures of the impellers and other basic components due to continuous emergency operation of those pumps. Emergency operation refers to the operation of the section pump in the critical rotor axial position caused by unsatisfactory hydraulic balancing device health. The main causes of the continuous emergency operation of the section pumps JSH 200 produced by Mackley Pump and the section pump TSNSK-350-1100 produced by Link-Product are failures of rotor axial position sensors. In case of a sensor failure, automatic protection of the pump becomes impossible when the rotor is in its critical axial position. The present article aims to prove that temperatures of the rear bearing of the section pump can be a diagnostic criterion of its emergency operation.
\end{abstract}

Keywords - section pump, axial shift, wear, bearing, temperature.

\section{INTRODUCTION}

Pump operating experience for ALROSA's mines shows that their distinctive feature is a low mean operating time of section pumps installed in pump chambers of the main mine drainage system of the Udachny mine (Fig. 1) and Mir mine (Fig. 2) [1].

Frequent major repairs are rather expensive. For one section pump, their costs range from two to million rubles depending on wear and model of the pump. The Mir mine and Udachny mine annually spend about 20 million rubles for major repairs of section pumps of the main mine drainage.

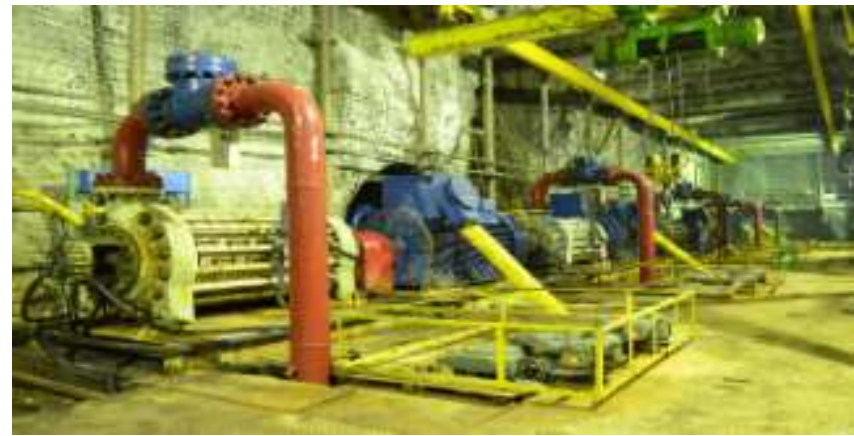

Fig. 1. Pump chamber of the main mine drainage system at the Udachny mine

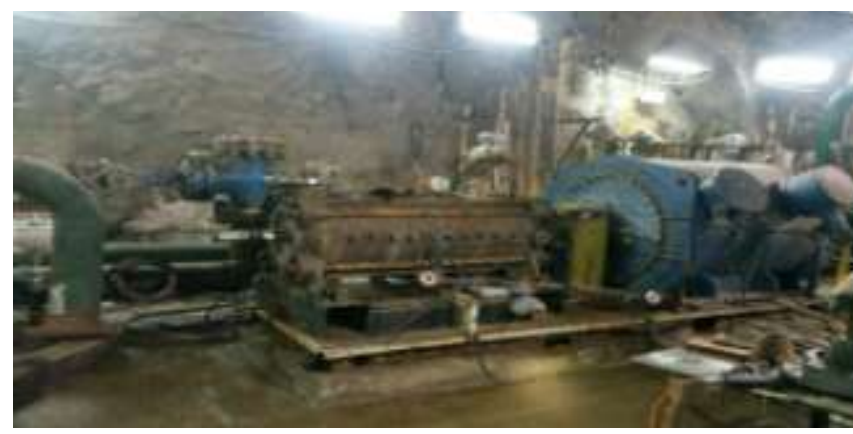

Fig. 2. Pump chamber of the main mine drainage system at the Mir mine

Statistical analysis showed that the main cause of frequent expensive major repairs of section pumps is failures of the impellers (Fig. 3 and Fig. 4) and other basic components due to continuous emergency operation of the pumps. Emergency operation refers to the operation of the section pump when its rotor is in critical axial position $(2.8 \ldots 3 \mathrm{~mm})$ relative to the suction side.

An increase in rotor axial shift to the critical values results from unsatisfactory state of pump hydraulic balancing device unit' parts [2] 
Failure of hydraulic balancing device unit' parts is usually associated with its hydroabrasive wear (Fig. 5), the intensity of which depends on a number of factors, such as: concentration of particulates and microhardness of particulates. The results of physical and chemical analysis of mine water samples taken at the Udachny mine (Fig. 6), Inter mine and Mir mine show that the concentration of particulates in the total volume of liquid ranges from 0.43 to $4.27 \%(5.3-52.3 \mathrm{~g} / \mathrm{l})$ depending on the sample section.

Microhardness of particulates ranges from 7 to $10 \mathrm{GPa}$.

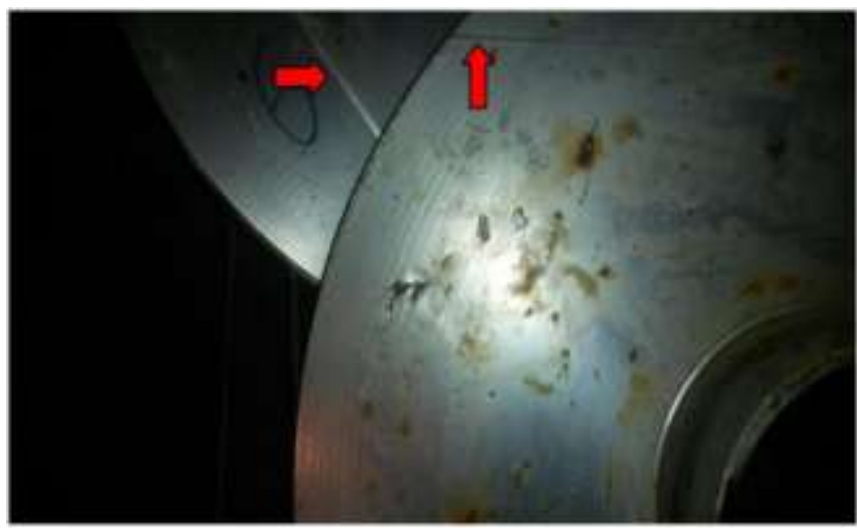

Fig. 3. Abrasive wear of the impellers

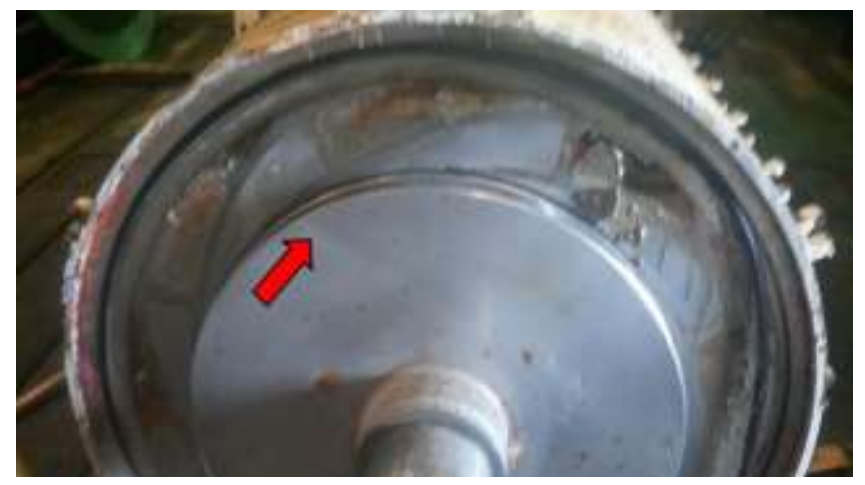

Fig. 4. Deformation of the impeller

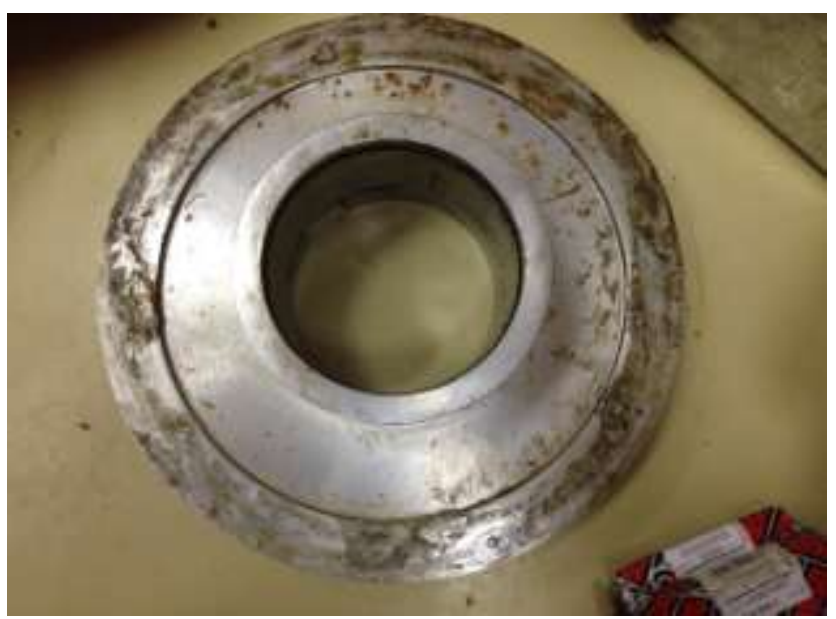

Fig. 5. Intensive hydroabrasive wear of the hydraulic balancing device disk

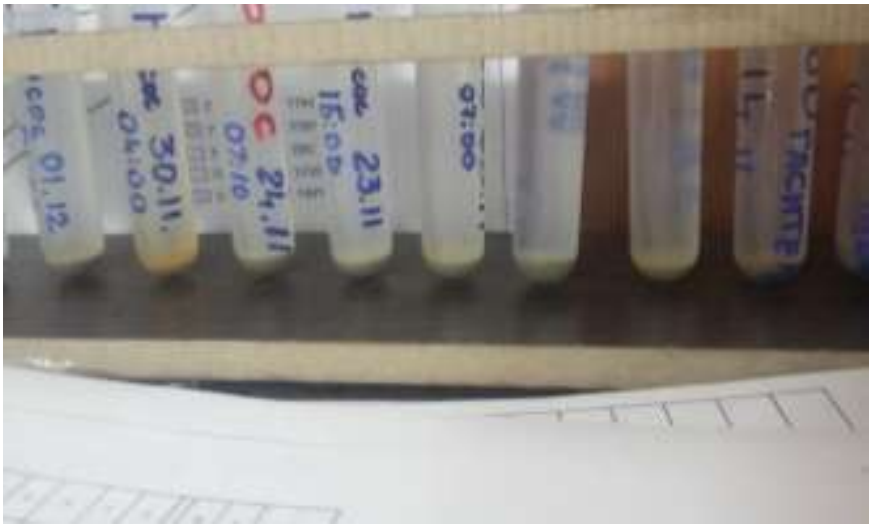

Fig. 6. Settled solid phase of mine waters at the Udachny mine under laboratorial conditions

For the pump chamber of the main mine drainage system at the Udachny mine, the continuous emergency operation of the JSH 200 section pump produced by Mackley Pumps and TSNS(K) 350-1100 section pump produced by Link-Product is due to regular failures of rotor axial position sensors.

In case of a sensor failure, automatic protection of the section pump becomes impossible when the rotor is in its critical axial position.

At present, the rotor axial position can be identified by means of a parametric diagnostics.

According to [3, 4], parametric diagnostics is widely used when assessing the health of a wide variety of rotation machines. Parametric diagnostics of the section pump as well as any other centrifugal pump refers to monitoring of its hydraulic parameters, in particular efficiency and output pressure.

In case of deviation of these values from standard ones, the section pump should be cut off, and its rotor - inspected.

Surveyed workers of the Udachny mine, Inter mine and Mir mine said that frequent failures of pumps with smooth start (pumps of the main mine drainage system of the Udachny mine and Mir mine) have a negative effect on the health of a hydraulic balancing device as pump acceleration and deceleration cause a short contact of its disc and ring.

Figure 7 shows that the values of the mean operating time of the hydraulic balancing device until failures of the section pumps with direct start exceed the values of the mean operating time of the hydraulic balancing device until failures of the section pumps with smooth start.

Acceleration and deceleration time for the pumps of the main mine drainage system of the Udachny mine and Mir mine ranges from 10 to $20 \mathrm{sec}$.

Dependences developed by the authors on the basis of the processed statistical data (Fig. 8 and Fig. 9) show that the rotor axial shift for JSH 200 pumps numbered 0 (blue color), 1 (red color), 3 (black color), 5 (brown color) and a TSNS(K) 3501100 pump numbered 4 (yellow color) do not correlate enough with the above-mentioned hydraulic parameters which is contrary to the conclusions in $[3,4]$. 
Surveyed workers of the Udachny mine said that this variety of hydraulic parameters (see Fig. 8 and Fig. 9) results from changeable pressure resistance in the pipe system as mine water pumping is performed by one of the technological drainage schemes differing from each other in length, number of isolation valves, bends, etc.

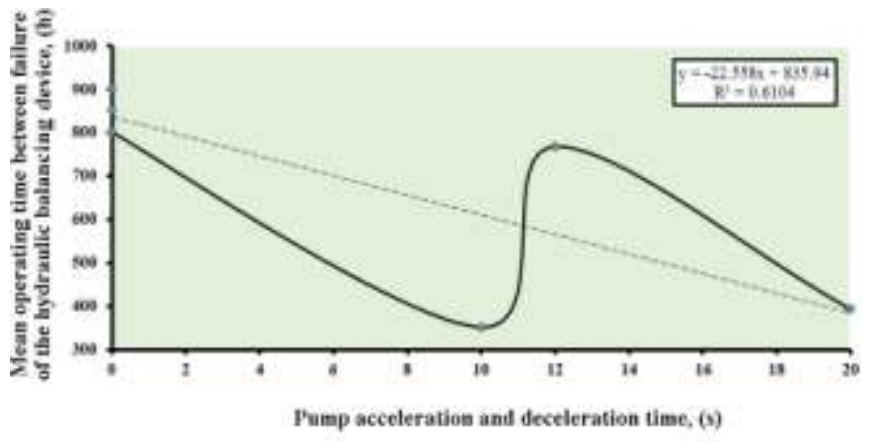

Fig. 7. Dependence of the mean operating time of the hydraulic balancing device on pump acceleration and deceleration time

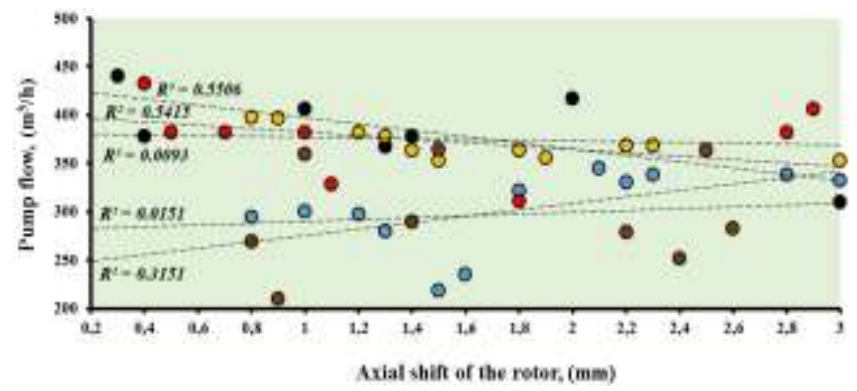

Fig. 8. Dependence of pump flow on the rotor axial shift

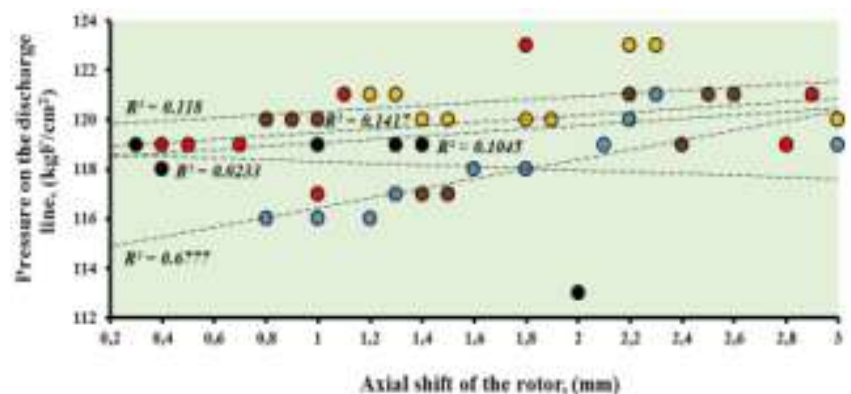

Fig. 9. Dependence of pressure on the discharge line on the rotor axial shift

Critical rotor axial shift can be determined by changes of water flow in the unloading pipe (Fig. 10). A decrease in water flow relative to its standard value $\left(4 \ldots 6 \mathrm{~m}^{3} / \mathrm{h}\right)$ is due to the clearance gap between the disc and ring of the hydraulic balancing device.

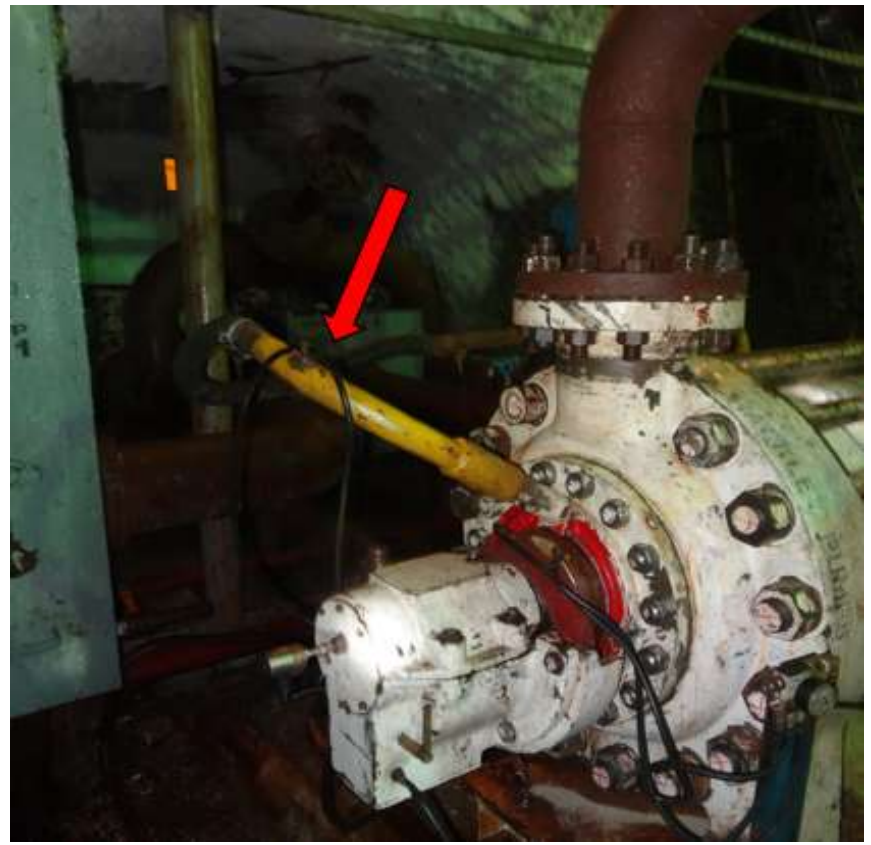

Fig. 10. Unloading pipe of the JSH-200 section pump produced by Mackley Pumps

Clearance gap is caused by rotor shifts to the suction side. Thus, zero water flow in the unloading pipe is a diagnostic criterion for the critical rotor axial shift.

As the evidence from practice shows, the main causes of a significant water flow decrease in unloading pipes of the section pumps under study are wear of hydraulic seal rings of the impellers and clogging of mesh filters with large particulates (Fig. 11).

A decrease in the clearance gap between the hydraulic balancing ring and disc is followed by an increase in water temperature in the unloader. Pump operation experience at the Udachny mine shows that water temperature in the unloading pipe can be $60^{\circ} \mathrm{C}$ during acceleration and deceleration of the pump unit. Mean water temperature in unloading pipes of the section pumps is about $0{ }^{\circ} \mathrm{C}$.

At the Mir mine, unscheduled shutdown and inspection of the pump unit are carried out when the temperature in the unloading pipe is over $20^{\circ} \mathrm{C}$.

Surveyed workers of the Mir mine and Udachny mine said that the main cause of an increase in rotor axial shifts is mechanical wear of the hydraulic balancing ring and disc. Their wear decreases pressure in the unloader due to the end clearance (Fig. 12) which impairs the loading capacity of the unloader. 


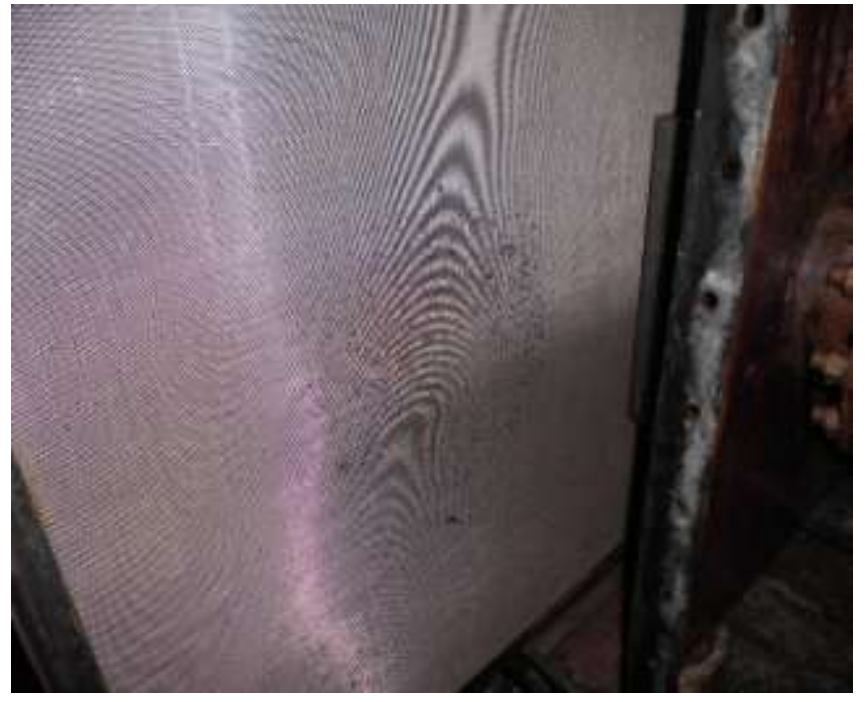

Fig. 11. Clogging of a mesh filter with large particulates

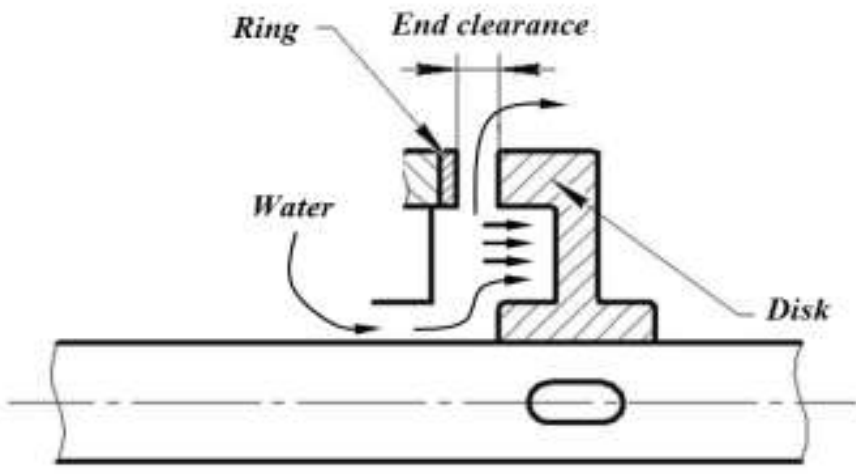

Fig. 12. Diagram of an unloader of the section pump

Pressure boost in the unloader results from a water flow increase in the unloading pipe. Thus, we can argue that water flow increase in the unloading pipe is followed by the critical rotor axial shift.

As the evidence from practice shows, flowmeters installed on unloading pipes of the section pumps were defective because of small flow capacity. Maximum flow capacity of flowmeters was about $9 \mathrm{~m}^{3} / \mathrm{h}$. At present, all flowmeters on unloading pipes were dismantled.

Due to high costs, the Udachny mine is not going to purchase large capacity flowmeters. One explosion-proof flowmeter costs about 400000 rubles. Besides, purchase of new flowmeters should be followed by resetting the Becker mining system (Fig. 13) which is time consuming.

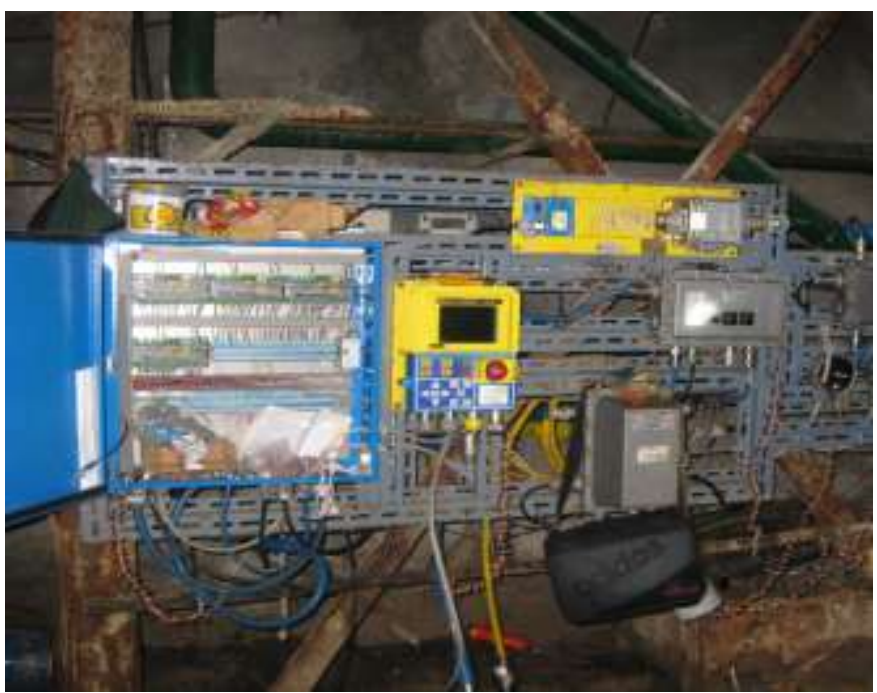

Fig. 13. Becker pumping equipment automation

Unwanted sound in the flow part of the section pump is one more diagnostic criterion of its emergency operation. Delayed identification of that diagnostic criterion can cause complete pump failure.

To sum up, in order to enhance performance of section pumps, we have to identify new diagnostic criteria for their emergency operation as existing diagnostic criteria are not always appropriate.

\section{RESULTS AND DISCUSSION}

Except for rotor axial position sensors, flowmeters and manometers, section pumps are equipped with other sensors. They are vibration and heat sensors installed on bearings which are most sensitive to failures of rotation machines, including centrifugal ones [5-11].

According to $[10,11]$, elevated vibration or temperature of the bearing are typical diagnostic criteria of the emergency operation of the section pumps. Figures 14 and 15 show that the maximum Root Mean Square (RMS) value of the vibration velocity of pump bearings is observed for the axial shift of $0.8 \ldots 2.5 \mathrm{~mm}$. 


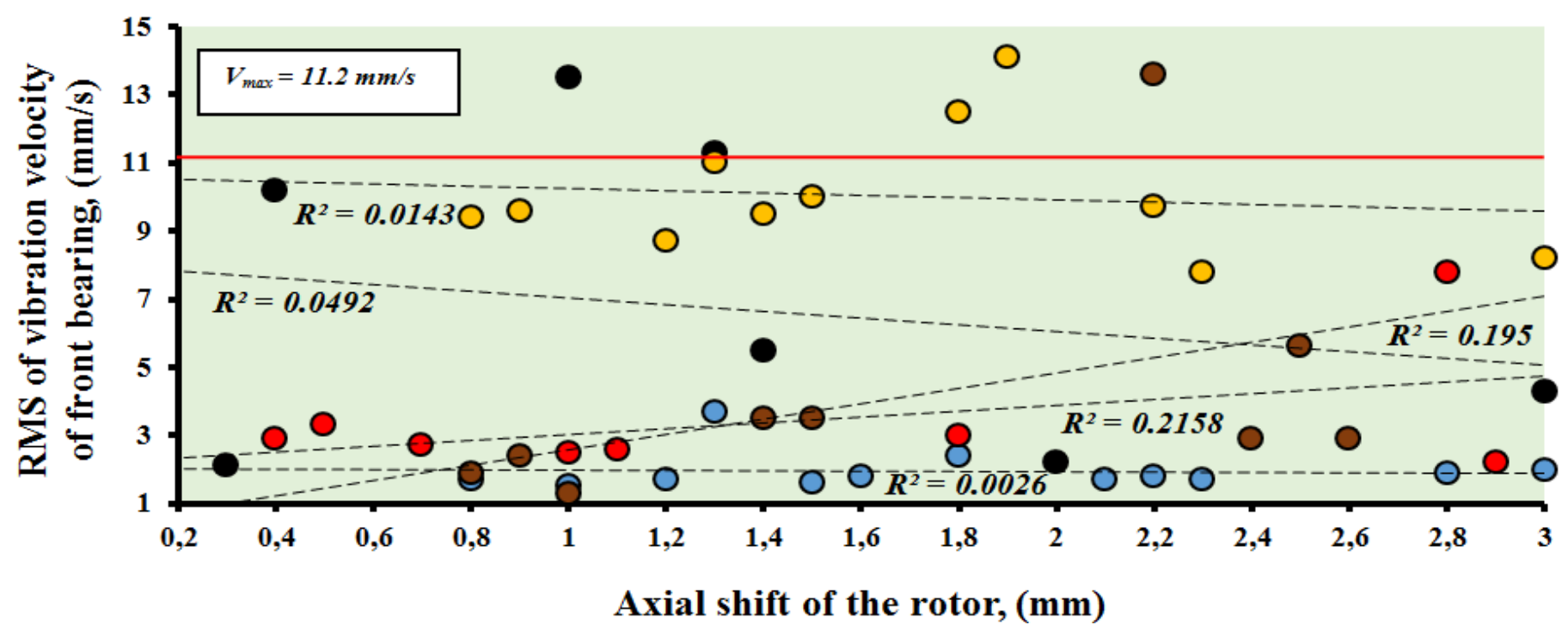

Fig. 14. Dependence of the RMS value of vibration velosity of front bearing on the rotor axial shift

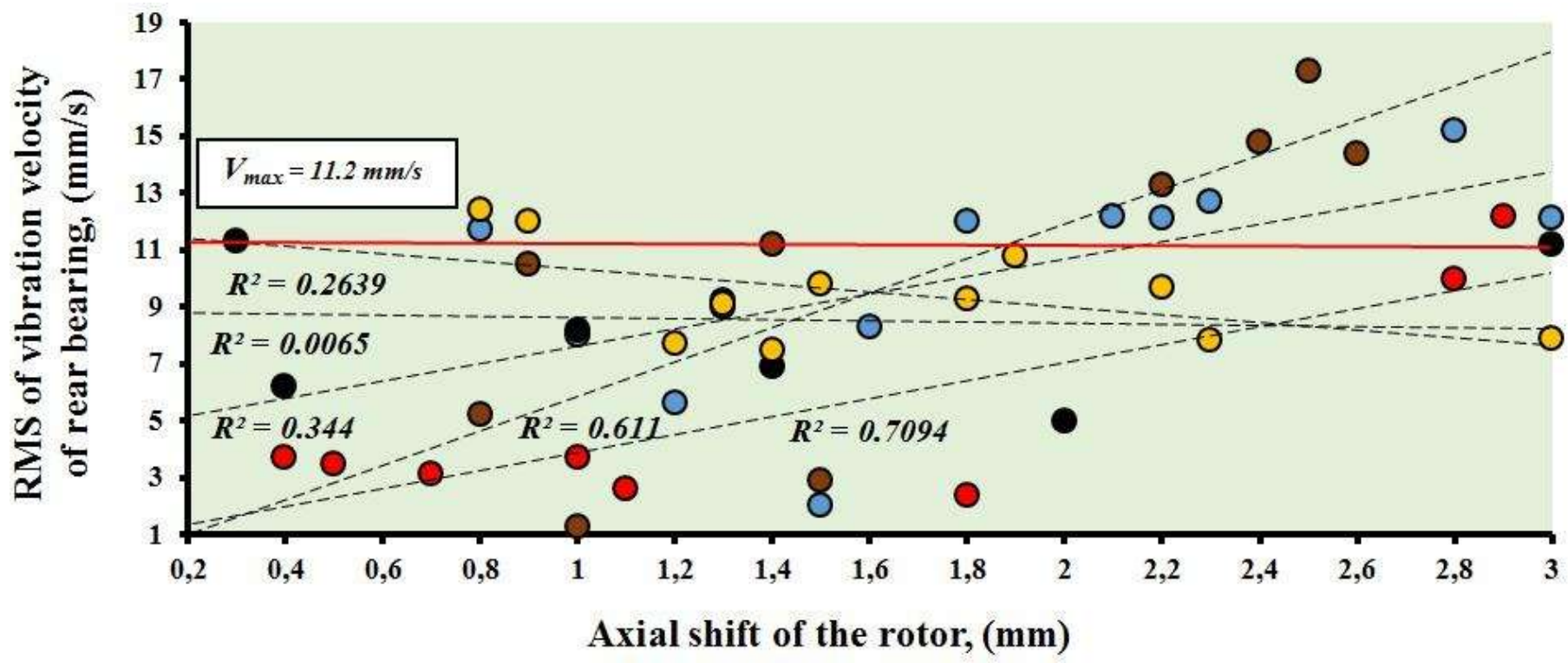

Fig. 15. Dependence of the RMS value of vibration velosity of rear bearing on the rotor axial shift

Thus, one can argue that a significant increase in RMS values of the vibration velocity of both rear and front pump bearings is not a typical criterion of their emergency operation.

Figures 14 and 15 show that RMS values of the vibration velocity of pump bearings range from 1.3 to $17.3 \mathrm{~mm} / \mathrm{s}$, while the maximum permissible RMS value is $11.2 \mathrm{~mm} / \mathrm{s}$.

Pump vibration tests performed by highly skilled professionals from city Mirny showed that at the Udachny mine, the section pumps operate under non-permissible RMS values of the vibration velocity due to wrong values of vibration sensors because of their frequent failures.

Thus, at present, vibration diagnostics used to identify typical diagnostic criteria of emergency operation of the section pumps under study is not efficient.

Statistical research results presented in Figures 16 and 17 show that emergency operation of the section pumps often results from an increase in rear bearing temperature up to 60$63{ }^{\circ} \mathrm{C}$. Thus, an increase in rear bearing temperature up to 60 ${ }^{\circ} \mathrm{C}$ can be considered a new diagnostic criterion of emergency operation of the section pumps. 


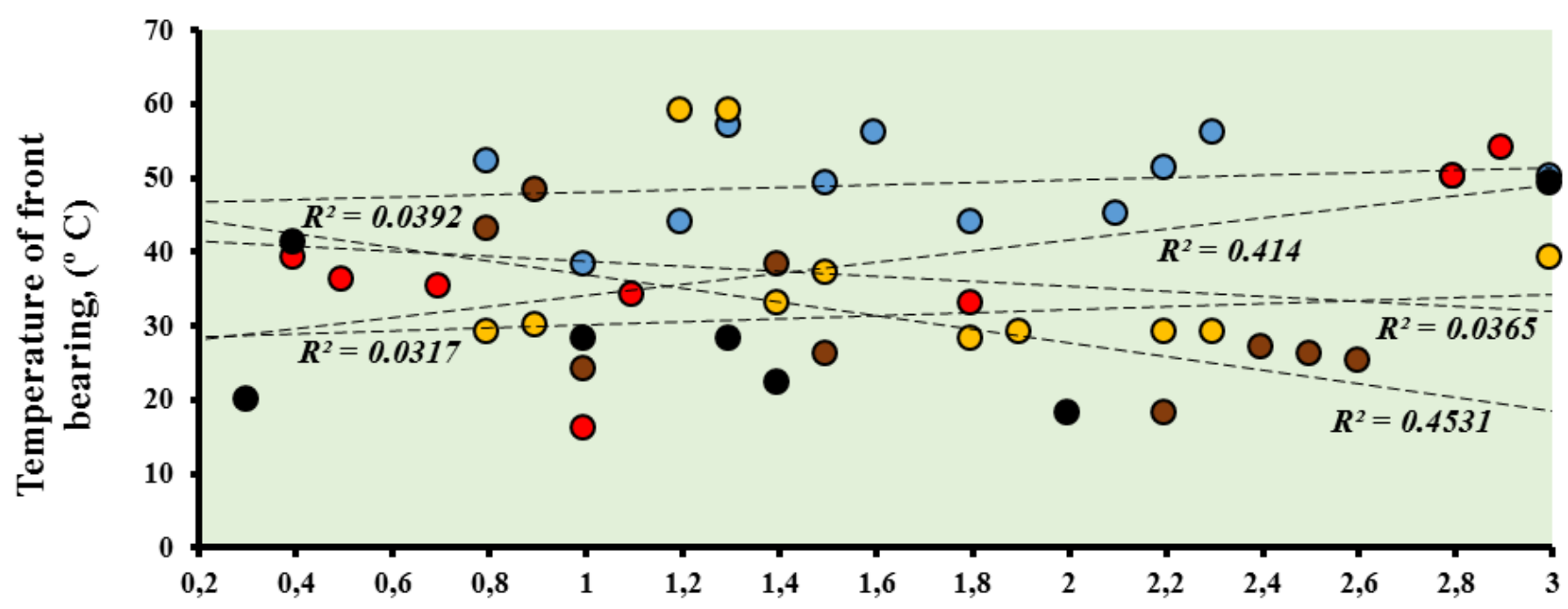

Axial shift of the rotor, $(\mathrm{mm})$

Fig. 16. Dependence of front bearing temperature on the rotor axial shift

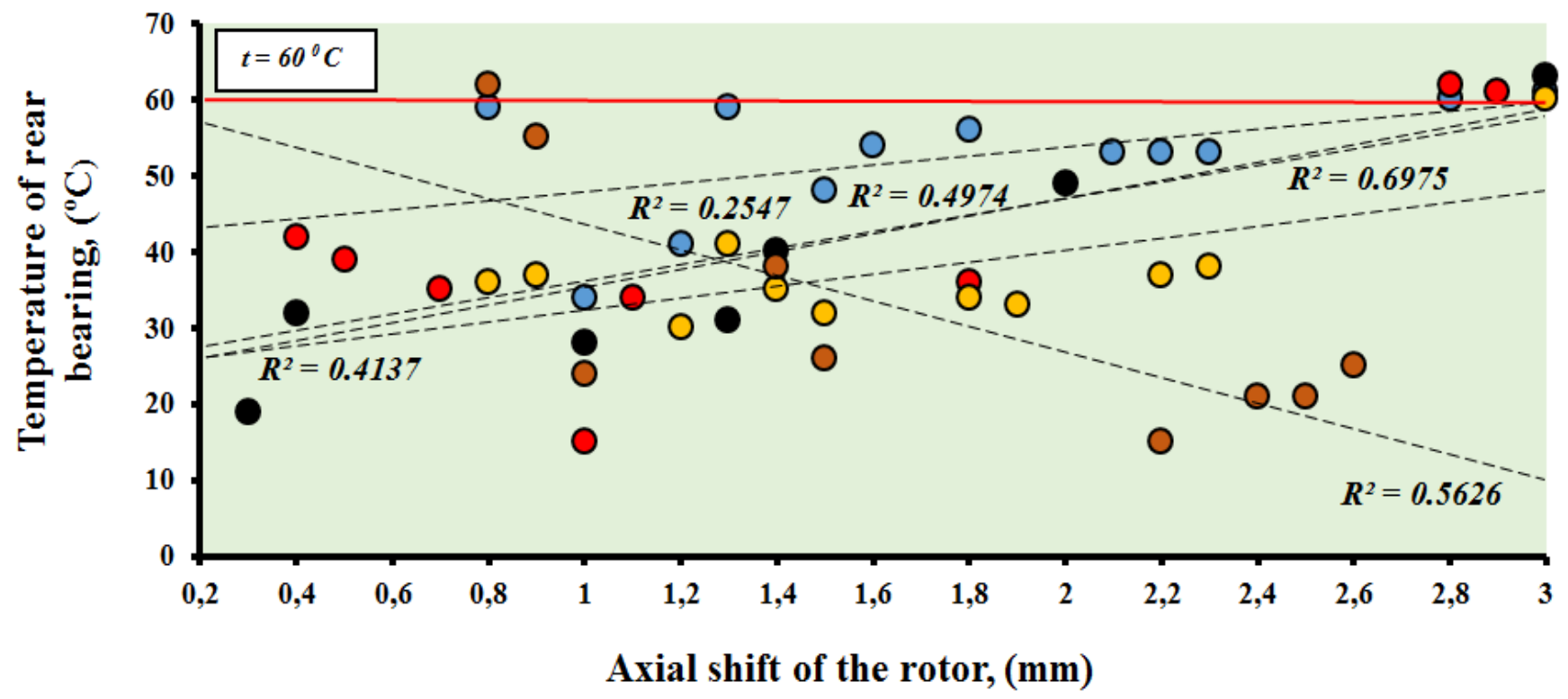

Fig. 17. Dependence of rear bearing temperature on the rotor axial shift

One should remember that an increase in bearing temperature could result from both rotor axial shift and mecahnical particulates which cause abrasion and heating the metal.

When the rear bearing temperature is $60{ }^{\circ} \mathrm{C}$, one should take into account concomitant characteristics of the emergency operation of the pump as well.

According to the recommendations of LLC Link-Product, the Udachny and Mir mines' leading supplier of pump's equipment, diagnostic criteria of emergency operation are elevated water temperature and flow in the unloading pipe.

Laboratory tests of $\mathrm{K} 8 / 18$ showed that a water flow increase in the pipe simulating an unloading pipe causes elevated vibrations, more specifically RMS values of the vibration velocity (Fig. 18).

The results of laboratory tests are presented in Fig. 19. 


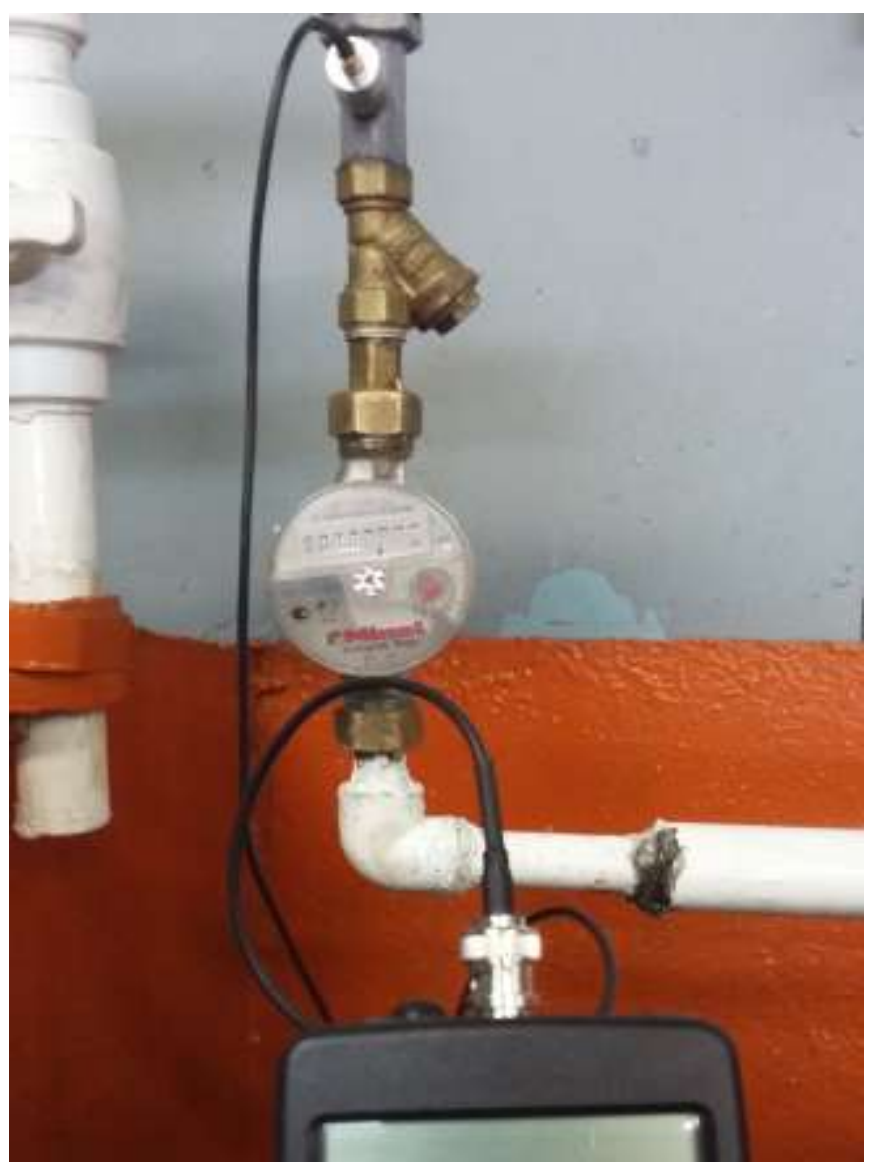

Fig. 18. Research of the RMS values of the pipe vibration velosity

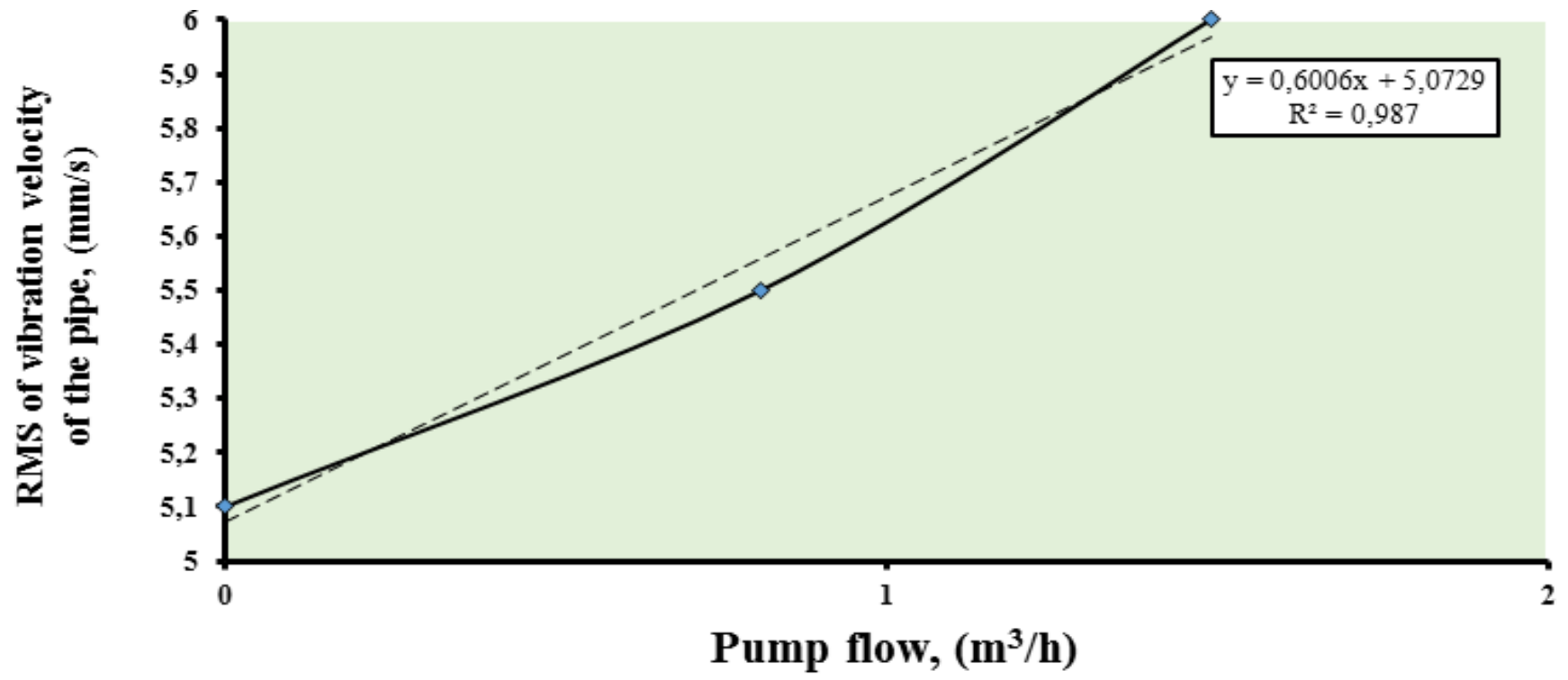

Fig. 19. Dependence of the RMS value of the pipe vibration velocity on the pump flow

Thus, at rear bearing temperature of $60{ }^{\circ} \mathrm{C}$ and elevated vibration or temperature of the unloader, the pump should be shut down at once and thoroughly inspected.

\section{CONCLUSION}

The authors conclude that:
1. Use of parametric and vibration diagnostics for identifying typical diagnostic criteria of emergency operation of the section pumps is not efficient.

2. Rear bearing temperature of $60{ }^{\circ} \mathrm{C}$ and elevated vibration or temperature of the unloader could be a diagnostic 
criterion of emergency operation of the section pump of the main mine drainage system.

\section{References}

[1] N.P. Ovchinnikov, M.A. Vikulov, Yu.S. Bochkarev and G.P. Dovidenko, "Experimental studies of operating properties of pumping unit with worn impeller”, Mining journal, vol. 9, pp. 85-88, 2016.

[2] A.V. Dolganov, A.O. Eslentyev, E.O. Cherakov and E.Yu. Toropov, "Analysis of effectiveness of dumping devices of mine centrifugal sectional pumps", News of the Ural state mining university, vol. 2 (34), pp. $31-35,2014$

[3] S.S. Menshikov "Hydrotransport slurry pumps parametrical diagnostics methods", Mineral processing, vol. 2, pp. 37-39, 2012.

[4] S.S. Menshikov, M.A. Vasilyeva, "Coefficient of technical condition of the slurry pumps in hydrotransport of ore tails", Journal of mining institute, vol. 209, pp. 193-196, 2014.

[5] S. Fabian, P. Čačko, "Experimental measurement and examination of independent and combined interaction of vibrodiagnostic and tribotechical methods", Applied Mechanics and Materials, vol. 308, pp. 51-56, 2013.
[6] G. Janicki, A. Perzouvanis, B. Mason and M.K. Ebrahimi, "Turbine blade vibration measurement methods for turbocharges", American Journal of Sensor Technology, vol. 2(2), pp. 13-19, 2014.

[7] T. Galka, "Influence of load and interference in vibration-based diagnostic of rotating machines", Advances and applications in mechanical engineering and technology, vol. 3(1/2), pp. 1-19, 2011.

[8] H. Yuan, W. Yang, T. Zhao, M. Liang, "Effects of stator-rotor interaction on unsteady aerodynamic load of compressor rotor blades", Journal of vibroengineering, vol. 17(5), pp. 2591-2608, 2015.

[9] P. Zegarač Nickola, "Research into the causes of increased vibration levels on the diesel-electric generators set at the air traffic control Belgrade airport", Vojnotehnički glasnik, vol. 64(2), pp. 465-482, 2016.

[10] R.V. Biryukov, Yu.V. Kiselev, "Temperature diagnostics of gas turbine engine bearings", Scientific bulletin of the Moscow state technical university of civil aviation, vol. 205, pp. 55-61, 2014.

[11] P.B. Gerike, "The results of vibration diagnostics of centrifugal pumps in relation to the creation of a single criterion for assessing the actual technical condition of this equipment", Bulletin of Kuzbass state technical university, vol. 6, pp. 89-96, 2016. 